\title{
STUTTERING INTERVENTION IN THREE SERVICE DELIVERY MODELS (DIRECT, HYBRID, AND TELEPRACTICE): TWO CASE STUDIES
}

\author{
DANIEL T. VALENTINE, PHD \\ UNIVERSITY OF MONTEVALLO, MONTEVALLO, AL, USA
}

\section{ABSTRACT}

This study assessed outcomes in stuttering intervention across three service delivery models: direct, hybrid, and telepractice for two 11-year old children who stutter. The goal of the study was to investigate whether short-term goals were maintained through the telepractice sessions. The Stuttering Severity Instrument, Fourth Edition (SSI-4) was administered to each child before and after each intervention period and weekly fluency samples (percentage of stuttered syllables in a monologue) were obtained in each of the 10-week intervention periods. In addition, the Communication Attitudes TestRevised was used to assess the children's attitudes toward speaking. Following the telepractice period, parents and children completed a questionnaire concerning the therapy experience via telepractice. Both children continued to improve fluency as measured by the weekly fluency samples. SSI-4 severity ratings improved for one child and remained consistent for the other. These outcomes appear to demonstrate that telepractice is viable for improving and maintaining fluency.

Keywords: Fluency, stuttering, telepractice, telerehabilitation

As access to faster Internet connection grows and software applications for communication become freely available, more and more healthcare professionals have begun to experiment with telepractice. Telepractice, as defined by the American Speech-Language-Hearing Association (ASHA, 2014) is designed to use telecommunications technology to link "clinician to client/patient, or clinician to clinician for assessment, intervention, and/or consultation" (p.1). Over the past 15 years researchers have explored the use of telepractice across various communication disorders, such as neurogenic communication disorders (Armfield, Gray, \& Smith, 2012; Georgeadis, Brennan, Barker, \& Baron, 2004; Hill, Theodoros, Russell, Cahill, \& Ward, 2006; Theodoros, Hill, Russell, Ward, \& Wooten, 2008; Wertz et al., 1992); voice disorders (Halpern, et al., 2012; Howell, Tripoliti, \& Pring, 2009; Mashima, Birkmire-Peters, Holtel, \& Syms, 1999); speech-language disorders of school-age children (Grogan-Johnson et al., 2009); and stuttering disorders (Carey, O’Brian, Onslow, Block, Jones, \& Packman, 2012; Lewis, Packman, Onslow, Simpson, \& Jones, 2008; Irani \& Gabel, 2011; O’Brian, Onslow, \& Packman, 2008; Sicotte, Lehoux, Fortier-Blanc, \& Leblanc, 2003; Wilson, Onslow, \& Lincoln, 2004). The benefits and practicality of this service delivery model (e.g., ease of scheduling and access to treatment) have been discussed in the literature (Blaisier,
Behl, \& Callow-Heusser, 2013; Kully, 2002). At the same time, current barriers to telepractice (e.g., Internet connection difficulties; lack of bandwidth; privacy concerns; the need for multiple professional licenses when providing services across state lines; and lack of payment for services) have also raised concerns with this service delivery model (Cohn, 2012; Cohn, Brannon \& Cason, 2011; Denton, 2003).

Researchers have explored the viability and effectiveness of telepractice for providing stuttering intervention in various service delivery models. These have included stuttering intervention via: (1) telephone consultation along with the exchange of video recording; (2) videoconferencing at remote sites; and (3) the use of Internet software for video and audio communication within the client's home environment. Four studies have investigated the success of the Lidcombe Program via telepractice with the primary medium being conferencing over the telephone, the exchange of either audio or video recording by mail, and via webcam. The Lidcombe Program trains parents to provide verbal contingencies to their children who stutter to facilitate stuttered free speech (Onslow, Packman, \& Harrison, 2003). The effectiveness of this protocol for preschool children who demonstrate beginning stuttering has revealed significant reductions of 
disfluencies when compared to natural recovery (Harris, Onslow, Packman, Harrison, \& Menzies, 2002; Jones et al., 2005; Lincoln \& Onslow, 1997). An early study by Harrison, Wilson, and Onslow (1999) adapted the Lidcombe Program for a 5 year 10 month old child who had been stuttering for 4 years. All consultations and instructions for the program were conducted by telephone and through video recordings. After 9 months the child demonstrated significantly reduced stuttering and maintained less than 1\% disfluencies after 23 months post-treatment. In a follow-up study, Wilson, Onslow, and Lincoln (2004) again modified the Lidcombe Program for telepractice and provided services to five children ranging between the ages of 3 years 5 months to 5 years 7 months. Thirteen families withdrew from the study for various reasons (e.g., illness, poor compliance with home recordings, natural recovery of stuttering). Some of the adaptations included the elimination of clinic visits, consultations with parents over the telephone, use of recorded sessions rather than real-time assessment of severity ratings, and use of recorded sessions that were sent by mail of parents providing verbal contingencies to their children. All five participants who completed the program reached the required criteria for completing Phase I of the Lidcombe Program (although treatment fidelity for one participant was very poor and his success was attributed more to natural recovery than to the intervention). The researchers concluded that the adaptation of the Lidcombe program for telepractice was successful for decreasing stuttering percentages at the completion of Phase I and at the 12-month post-treatment measurement.

To evaluate the efficacy of the Lidcombe Program when delivered via telepractice, Lewis, Packman, Onslow, Simpson, and Jones (2008) designed a randomized controlled study of nine children who were independently placed in a treatment group (eight completed) and 13 children (10 completed) who did not receive therapy. Adaptations to the Lidcombe program were similar to those made by Wilson et al. (2004). Six of the eight children in the intervention group completed Phase I of the program and met the criterion of decreasing stuttered syllables by at least $80 \%$ and only two out of 10 in the controlled group met this criterion. Other outcomes included a high favorability to the telepractice process (87\%) and a parental rating of child stuttering severity at the lowest level (i.e., 1). The authors concluded that children who do not have access to the traditional Lidcombe Program can receive an adaptation of the program and expect equally positive outcomes.

A recent clinical trial by O'Brian, Smith and Onslow (2014) administered the Lidcombe Program over the Internet via webcam delivery. The participants were three pre-school children diagnosed with beginning stuttering and the baseline percentage of stuttered syllables ranged from $2.6 \%$ to $4.1 \%$. The percentage of stuttered syllables was collected each week by the clinician while engaging with the child by webcam or by watching the child talk with his caregiver. In this study all three children completed Stage 1 and Stage 2 of the Lidcombe Program; however, the number of consultations was almost double the average number for children who received the Lidcombe Program in a clinic. The researchers suggested this might have been due to the small sample size, various behavioral and health issues with the children, or perhaps the clinician's lack of experience with delivering intervention over the Internet. Despite these limitations they concluded that webcam delivery of the Lidcombe Program "appears to offer a viable treatment for young children who stutter and who might otherwise have limited access to treatment" (p. 829).

Similar to the previous research, O'Brian, Packman, and Onslow (2008) investigated the efficacy of telepractice via telephone consultations and video recordings, but this time using the Camperdown Program with adults who stutter. The Camperdown Program teaches speech modification or speech restructuring through the use of prolonged speech (presented via a video exemplar) to develop natural sounding fluency with near zero stuttering moments in one fifth of the time when compared to similar programs (O'Brian, Onslow, Cream, \& Packman, 2003). Like the clinic-based program, the telepractice program includes: (1) teaching prolonged speech and self-evaluation scales, (2) practicing natural-sounding stuttered free speech, (3) generalization of stuttered-free speech, and (4) maintenance phase. The authors believe that the program is well suited to telepractice because participants need only use an audio or video exemplar of prolonged speech without in-person clinician instruction or modeling, and there are no measurements of speech rate or stuttering syllable counts during the treatment phases. Instead, these are replaced by a 9-point stuttering rating scale and naturalness scale (O'Brian et al., 2003). Participants in this study were 10 adults (nine with a history of previous therapy), ages 22 years to 48 years. Pretreatment percentage of stuttered syllables ranged from $2.4 \%$ to $10.8 \%$. The percentage of stuttered syllables and speaking rate was obtained from three pre-treatment and three post-treatment assessments and a 6-month post-treatment speaking assessment. During the treatment phase, telephone consultations with a clinician were, according to the authors, "introduced only when and if required" (p. 188). The group mean telephone contact averaged 8 hours. Seven of 10 participants decreased their percentage of stuttered syllables by more than $80 \%$ at the immediate post-treatment phase; four of 10 participants retained this level at the end of the 6-month post-treatment phase. The authors concluded that the telepractice model can offer a viable alternative to a clinic-based treatment program with a relatively short amount of clinician contact time. However, they cautioned that long-term fluency results were obtained in only four of the 10 participants. Selfreported stuttering severity with various speaking partners all demonstrated significant decreases for all participants immediately following the treatment phase. At the 6-month post-treatment phase, three participants reported increased severity in some speaking situations, but none returned to 
pre-treatment levels. One finding worth noting is that none of the participants in this study dropped out of the program, despite job changes, interstate moves, and illnesses. This is in contrast to the O'Brian et al. (2005) study of the Camperdown Program in which $30 \%$ of the participants did not complete the treatment program.

Carey and colleagues (2012) used an adaptation of the Camperdown Program to provide intervention to three adolescents (ages 13 years to 15 years) who stutter via Skype software for audio and visual Internet communication. Among the adaptations that had not been included in the O'Brian et al. (2008) study were: scheduled weekly treatment sessions with a licensed speech-language pathologist (SLP) via webcam, use of email to send speech samples, and parental involvement. All three participants demonstrated more than $80 \%$ reduction of stuttering from the pre-treatment measurements and two of the three maintained this level at or above the 12-month measurement period. The number of sessions from the pretreatment period to entry in the maintenance phase ranged between 13 to 24 sessions; the number of weeks ranged between 16 to 22 weeks. The reported number of clinician hours over this period ranged from 8:18 hours to 15:0 hours. Based on the results, the authors suggest that the Internet delivery model is an "efficacious, efficient, and appealing" ( $p$. 376) method of providing stuttering intervention.

An earlier research study that employed audio-visual intervention to remote sites was conducted by Sicotte, Lehoux, Fortier-Blanc, and Leblanc (2003). Participants attended one of two sites equipped with videoconferencing equipment. Six participants (ages 4,5,7,12,17, and 19 years) were assessed twice before treatment, twice after treatment and three times during the maintenance period. Their speech samples were video recorded and analyzed for stuttered syllables. Neither prior nor current treatment approaches were reported. Four participants received 20 weekly sessions and two received 12 weekly sessions. All participants decreased stuttering levels from pre-treatment (range $13 \%$ to $36 \%$ ) to post-treatment levels (range $2 \%$ $26 \%$ ). Only two of the six participants decreased or maintained the post-treatment level at the 6-month follow-up measurement. The authors were encouraged by the outcomes given the fewer than average number of treatment session to reduce the percentage of stuttered syllables and suggested that this service delivery model is a viable way to provide stuttering intervention. What is of particular interest in this study was the success of the intervention with younger children via audio-visual remote connections.

Finally, Irani and Gabel (2011) reported that telepractice is effective, especially in the maintenance phase of stuttering intervention. The participant in their study was a 21-year old male with a long history of stuttering who was enrolled in an intensive therapy program at a university clinic (Gabel, Irani, Palasik, Swartz, \& Hughes, 2010). Following the three week program, a 12-month maintenance phase was established; this included two weekly sessions for 6 months, and one weekly session for 6 months. The sessions "recycled" the elements of the intensive program based on client needs. All sessions were conducted using Skype software via Internet connections. Outcomes were obtained at the beginning and end of the intensive program and during the two 6-month interval periods during the maintenance phase. Measures included the percentage of stuttered syllables during various speaking situations, stuttering severity as measured by the Stuttering Severity Instrument-3 (SSI-3; Riley, 2009), and several outcome measures related to attitudes and emotions using the Overall Assessment of Speakers Experience of Stuttering (OASES; Yaruss \& Quesal, 2008). The percentage of stuttered syllables across various speaking situations decreased dramatically following the intensive program and continued to decline 6 months post-treatment with only a modest increase after 1 year post-treatment. The stuttering severity on the SSI-3 continued to show this same trend as did the responses from the OASES. While the authors acknowledged certain limitations of the study (e.g., single subject, occasional technical breakdowns, and restrictions on transfer activities) they nonetheless concluded that a telepractice-based service delivery model is a cost effective and efficient way to deliver stuttering intervention during a maintenance phase.

This study presents two case studies of school-age children who stutter and who received intervention at a university clinic. The fluency outcomes of the two children were analyzed across three service delivery models: (1) direct, (2) hybrid (i.e., direct and telepractice), and (3) telepractice only. In addition, qualitative data were obtained from parents and the children to understand their experience and satisfaction with the clinical services. The following research questions were addressed:

1. Was fluency increased, decreased, or maintained across the three service delivery models?

2. Did communication attitudes remain constant across the three service delivery models?

3. Did the parents of the children in this study express concerns with stuttering intervention via Internet technology?

4. Did the children in this study experience difficulties following directions or managing the technology during the telepractice sessions? 


\section{METHODS}

\section{PARTICIPANTS}

\section{PARTICIPANT 1}

The first participant was a female (11 years 3 months) at beginning of treatment with a reported onset of stuttering at age 4 years. She had previously received therapy in the school system ( $4^{\text {th }}$ grade), as well as with a private speechlanguage pathologist. It was reported that she consistently received grades of A's and B's in school classes and generally enjoyed her studies. Testing at the beginning of the treatment period included the Picture Peabody Vocabulary Test - 4 (PPVT-4; Dunn \& Dunn, 2007); a standard score of 131 placed her in the $98^{\text {th }}$ percentile. The Stuttering Severity Index-4 (SSI-4; Riley, 2009) was also administered and she scored a 23 (percentile rank of 41-60) which placed her in the moderate range. The participant was home-schooled the first two treatment periods of this study and (at her request) enrolled in a public school during the telepractice period. At no time during this study did she receive outside intervention for stuttering.

\section{PARTICIPANT 2}

The second participant was a male ( 11 years 2 months) at the beginning of treatment with a reported onset of stuttering at 6 years of age. He was enrolled in the public schools, but had received no prior therapeutic intervention. It was reported that he was in good academic standing and received A's and B's in school classes. Prior to beginning treatment the PPVT-4 was administered; a standard score of 114 placed him in the $82^{\text {nd }}$ percentile. His score on the SSI-4 was 21 (percentile rank of 41-60) which placed him in the moderate severity range.

Both participants had positive attitudes toward therapy and eagerly participated in all treatment activities.

\section{INTERVENTION SCHEDULE}

Intervention was conducted and data collected across three treatment periods over a 10 week period by graduate students studying speech-language pathology. During the first treatment period the children were seen two times a week (50 minutes sessions) at the University's Speech and Hearing Center. During the second treatment period, the children were seen once each week in the clinic and once each week (45-50 minute sessions) via telepractice. In the third treatment period, the children were scheduled to be seen three times each week (30 minute sessions) via telepractice. Soon after the third treatment period began, it became apparent that due to other obligations, the families were not going to be able to participate three times per week. Instead, the goal was adjusted to provide intervention two days a week for 45-50 minute sessions. Due to the nature of scheduling and the needs associated with providing clinical education to the graduate students, different graduate clinicians provided intervention across the three treatment periods.

\section{ASSESSMENT AND TREATMENT PROCEDURES}

The SSI-4 was administered on the campus facilities at the beginning of each of the three treatment periods and 2 months following the third treatment period. The SSI-4 provides a weighted score for the percentage of disfluencies in a conversation/monologue and a reading passage. It also weights the average of the three longest disfluencies and gives a quantitative score for physical concomitants. The cumulative score is then compared to a qualitative description of the severity of stuttering ranging from severe to moderately severe to mild disfluency. All SSI-4 assessments were completed on campus and the monologue from the SSI-4 was recorded and transcribed. Each analysis of the monologue that documented the percentage of stuttered syllables was reviewed and verified by the author, a licensed speech-language pathologist.

The Communication Attitudes Test-Revised (CAT-R; Brutten, 1985) was administered at the beginning of the direct treatment and hybrid periods and at the end of the telepractice period. This was done because there was only a short break between hybrid and telepractice periods and to capture any changes following the telepractice intervention session. The $C A T-R$ is a 35 -item true-false questionnaire which explores children's attitudes about how they communicate with their peers and adults. The mean score for children who stutter is 16.7 and the mean score for children who do not stutter is 8.71 ; therefore, the higher score represents a more negative attitude about the child's speech.

Each session included several activities where fluency data was obtained for short-term fluency goals (e.g., picture description, open-ended questions, sequencing, giving directions, etc.). However, only the stuttered syllables in a short monologue (approximately 120 words) were analyzed at the end of the weekly sessions to document the percentage of stuttered syllables. These data were obtained each session as per Yaruss's (1998) real-time analysis of speech fluency; only the last session of the week was reported. This fluency sample was obtained without clinician interruptions, questions, or feedback. Baseline for this task was taken at the beginning of each treatment period. Finally, following the telepractice treatment sessions, both parents and the children completed a survey asking questions concerning their experience of stuttering intervention via telepractice. 


\section{INTERVENTION STRATEGIES}

All intervention strategies were consistent across the three treatment periods and were developed by the primary researcher in cooperation with the participants and their caregivers.

Participant 1 primarily received a stuttering modification protocol to reduce the severity of the moment of stuttering. This client demonstrated a variety of stuttering types and the severity of the stuttering moments often varied as well. Consequently, analyzing the stuttering moment to understand how to modify it and reduce anxiety was a consistent goal in all of the sessions. Modification strategies included the use of flexible rate, prolonging a stuttering moment with a light contact, and an easy release (Guitar, 2013). Goals also targeted eliminating secondary behaviors such as lack of eye contact and hand motions to face and eyes, which were primarily present during the first treatment period. Communication attitudes were explored during weekly discussions of her speech journal, wherein she would describe both positive and negative speaking experiences and discuss them with the clinician. During the direct and hybrid intervention periods activities also targeted various speaking situations outside the clinic room.

Participant 2 responded very positively to goals that shaped fluency. Therapy used a modification of smooth easy speech (Schwartz, 1999) which included a gradual increase of rate with $100 \%$ fluency, exaggerated smooth initial production of words at the beginning of sentences and prolongation of vowel sounds. Communication attitudes were also targeted with weekly discussions of his speech journal where he would describe both positive and negative speaking experiences and discuss them with the clinician. Like Participant 1, during the direct and hybrid intervention periods, activities also targeted various speaking situations outside the clinic room.

\section{TECHNOLOGY}

Both participants had Internet connections in their homes and used personal laptop computers. The Internet connections were provided by a local Internet provider, however the speed of the connection was not known. The graduate clinicians used either personal laptop computers or personal iPads. The quality of the connection for the majority of the sessions was adequate to provide instruction and collect data; however, from time to time, there were delays in the transmission. If there was confusion between a delay in transmission and a stuttering moment, this was not counted in the percentage of stuttered syllables. If there were frequent interruptions in the connection during a session, the clinician and the participant would log-off and re-establish the connection; the Internet connection would often vastly improve following this procedure. The free program service Skype was used to place audio/video calls over the Internet. Prior to beginning the telepractice sessions, both the children and their caregivers signed a telepractice consent form which outlined the privacy issues of using telepractice via Skype. For example, this consent form informed the caregivers and participants that the transmission might be disrupted or distorted and could be intercepted by unauthorized persons.

\section{GRADUATE CLINICIAN TRAINING}

Prior to beginning intervention, all graduate clinicians reviewed the goals for their respective client. Training, by the author, included the identification of both core and secondary behaviors in stuttered speech. Clinicians were required to view video recordings and listen to audio recordings of people who stutter in order to identify various types of stuttering moments. They also practiced pseudostuttering. In addition, clinicians practiced basic methods in stuttering modification and fluency shaping and reviewed provided literature that was pertinent to stuttering intervention. Each clinician was trained to collect the percentage of stuttered syllables during "real-time" analysis, similar to the procedure described by Yaruss (1998). Reliability for data collection was monitored over the first two sessions by the author for each clinician; inter-rater agreement was not obtained for subsequent sessions.

All of the clinicians were familiar with the technology, via their experience with Internet connections, laptop computers, and iPads. Each was therefore comfortable with providing audio and visual prompts to their clients for clinical activities.

\section{RESULTS}

Figures 1 and 2 present the total SSI-4 score for Participant 1 and Participant 2 respectively. Participant 1 dramatically improved her fluency score following the first treatment period of direct treatment, but subsequently plateaued. Scores from the $S S I-4$ remained stable across all service delivery models. The SSI-4 improved from a score of 23 (moderate severity) to 15 (mild severity) at the 2-month post treatment follow-up. Participant 2 demonstrated greater improvement which represented a steady decrease in disfluencies. His SSI-4 score improved from 21 (moderate severity) to 9 (very mild) at the 2-month post treatment follow-up. 


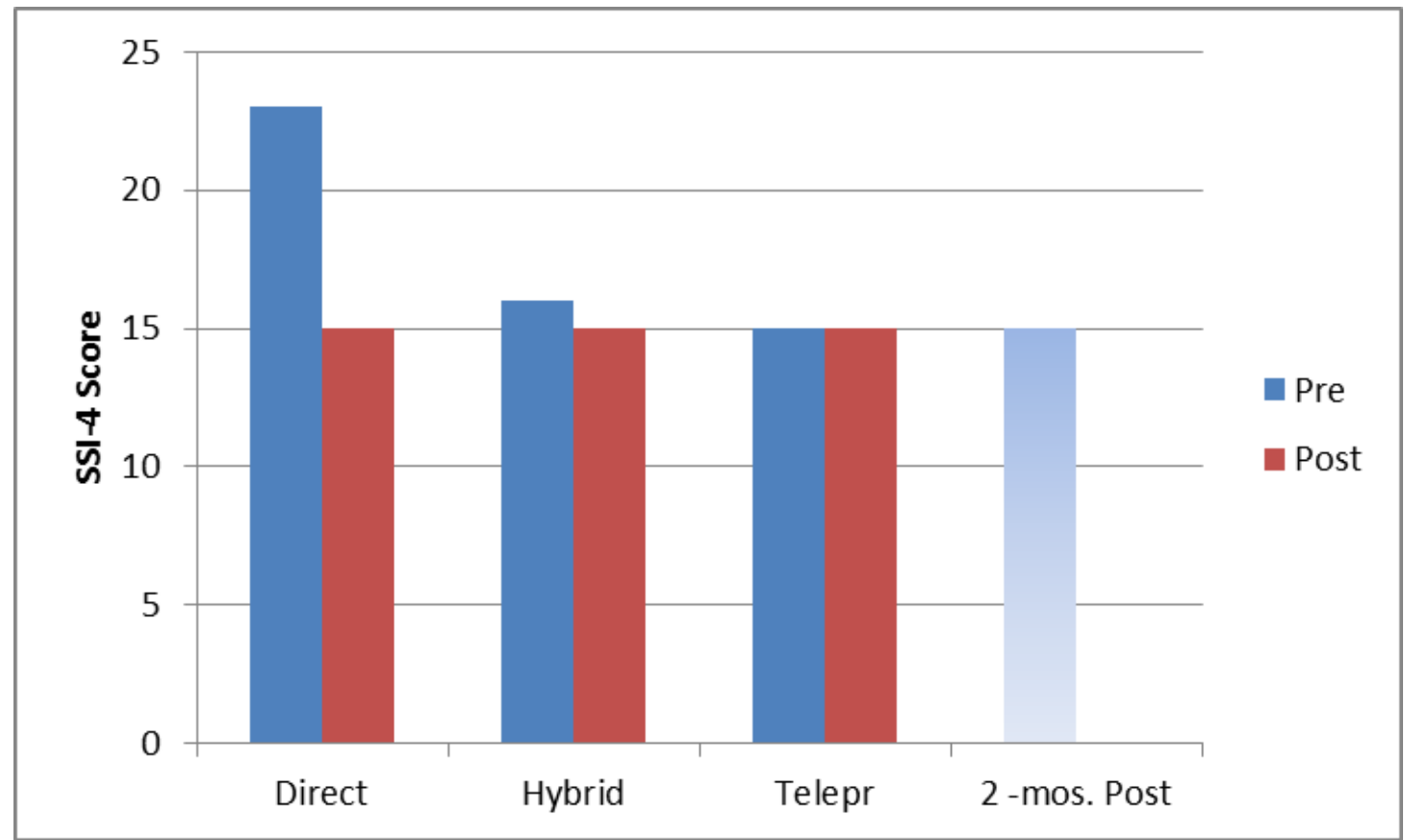

Figure 1. Participant 1 scores from Stuttering Severity Instrument-4 (SSI-4) across service delivery models (Telepr=Telepractice).

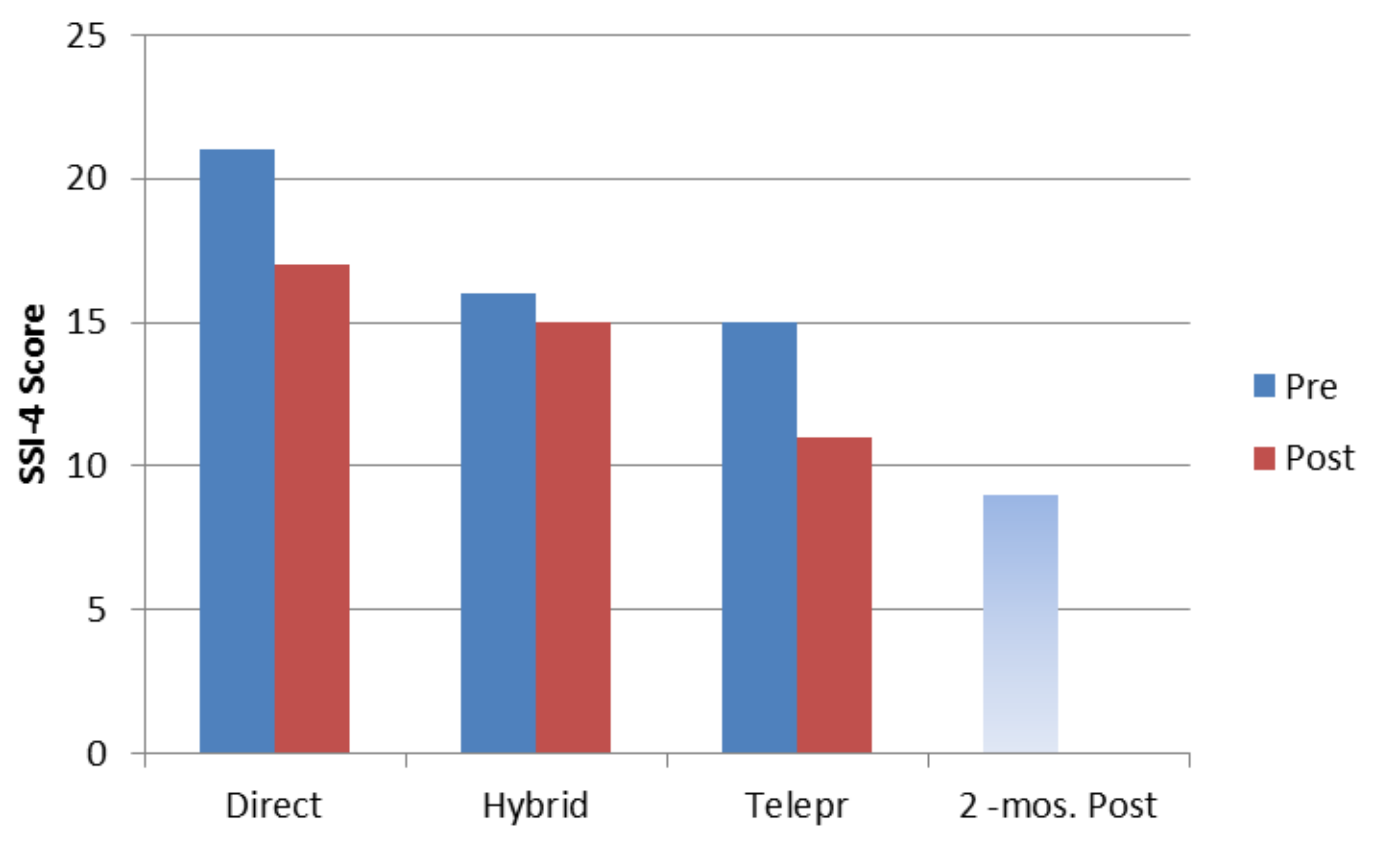

Figure 2. Participant 2 scores from Stuttering Severity Instrument-4 (SSI-4) across service delivery models (Telepr= Telepractice).

Figures 3 and 4 chart the percentage of stuttered syllables in a short monologue at the end of the weekly treatment sessions across the three service delivery models for Participant 1 and Participant 2, respectively. Participant 1 , whose baseline began at $17 \%$ stuttered syllables, steadily decreased the percentage of disfluencies across all service delivery models. The average percentage of disfluencies in a short monologue across ten treatment sessions in the direct service delivery model was $12.9 \%$. At the end of the hybrid model the average percentage was $9.8 \%$ (a $24.79 \%$ 
decrease in disfluencies), and at the end of the telepractice sessions the average percentage was $7.37 \%$ (a $24.79 \%$ decrease in disfluencies). The overall percentage of decrease in disfluencies from the direct model to the telepractice model was a $42.86 \%$ in disfluencies. Paired sample t- test data revealed significant progress from the direct to hybrid periods $(t(9)=2.72, p=.024)$, however, progress from the hybrid to telepractice periods was not significant $(t(9)=1.66, p=.132)$.

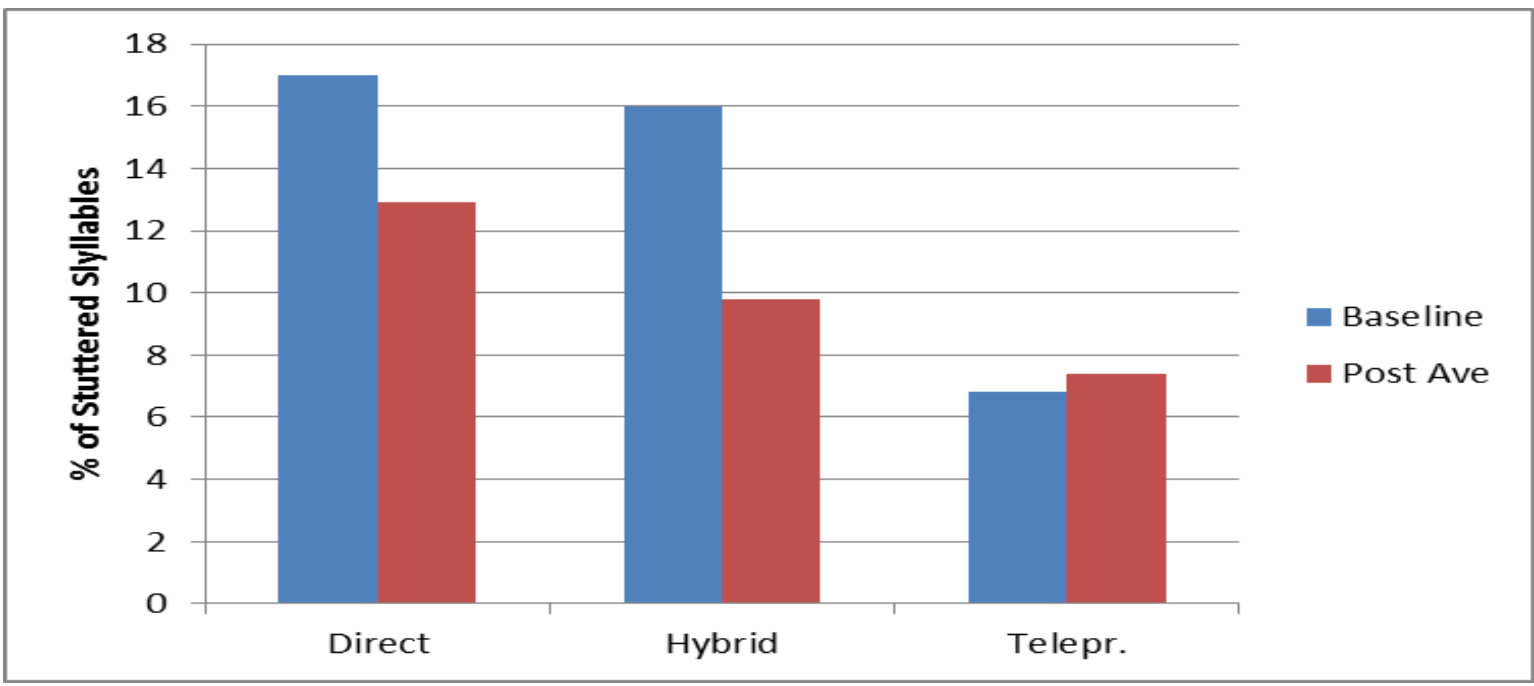

Figure 3. Participant 1: percentage of stuttered syllable in a speaking task (Post. Ave.=Post Average; Telepr=Telepractice).

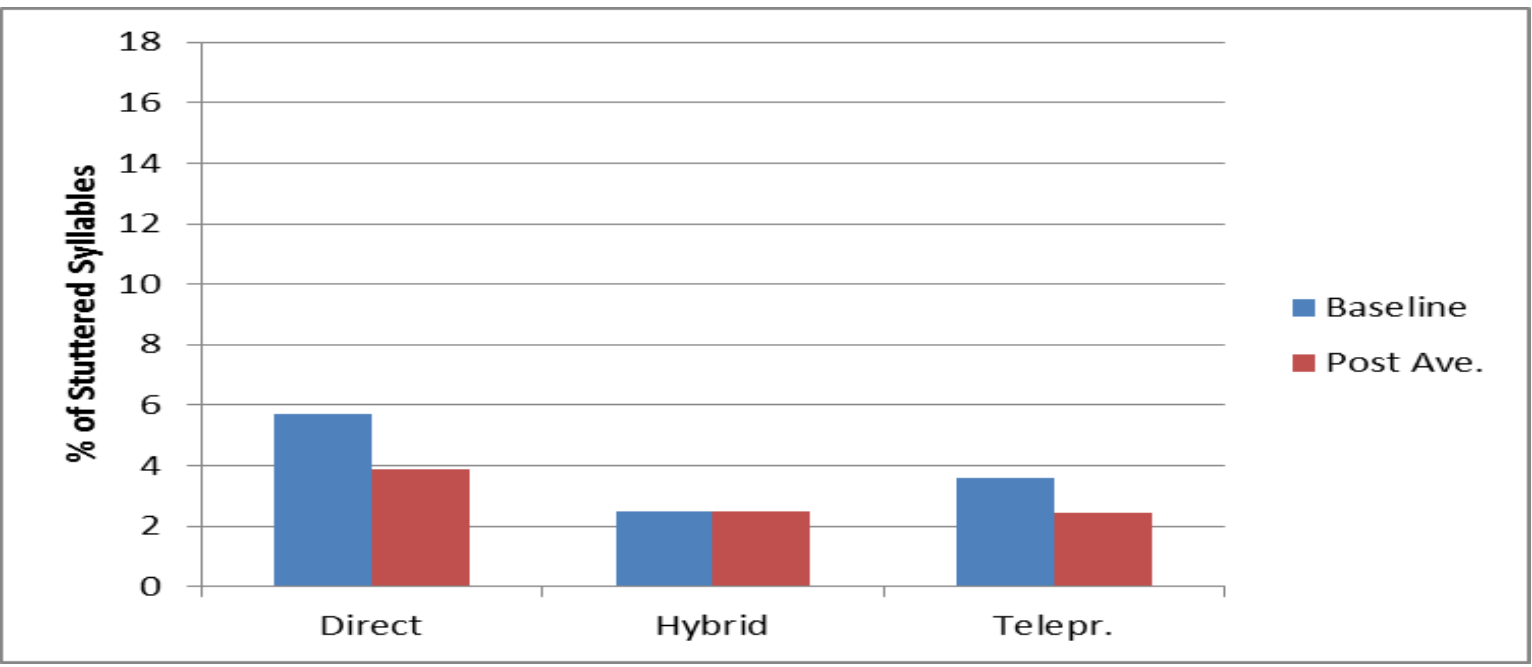

Figure 4. Participant 2: percentage of stuttered syllables in a speaking task (Post Ave= Post Average; Telepr= Telepractice).

Participant 2 began baseline at a much lower percentage of stuttered syllables (5.7\%), but also demonstrated a decrease in stuttered syllables across all service delivery models. The average percentage of disfluencies at the end of the direct sessions was 3.88\% and the ending percentage of disfluencies at the end of the hybrid session was $2.48 \%$ (a decrease of $36.08 \%$ ). During the telepractice sessions, Participant 2 was beginning to demonstrate less variability, ending with a session average of $2.46 \%$ stuttered syllables (an improvement from the hybrid sessions of only .80\%). Similar to Participant 1 , paired sample t-test data showed significant progress in reducing disfluencies from the direct to the hybrid periods $(t(9)=4.65), p=.001)$, but no significant progress from hybrid to telepractice periods $(\mathrm{t}(9)=.27, \mathrm{p}=.788$.

Although the results of stuttered syllables in a monologue demonstrated gradual reductions in disfluencies across the intervention periods, the fluency of each 
participant was highly variable. An effort was made to have the speaking situation be as neutral as possible (the participants were asked to speak for a few minutes on a topic of their choice) and thereby control for subject matter that might be more emotionally charged. Figures 5 and 6 represent the variability of stuttered syllables across the intervention periods.

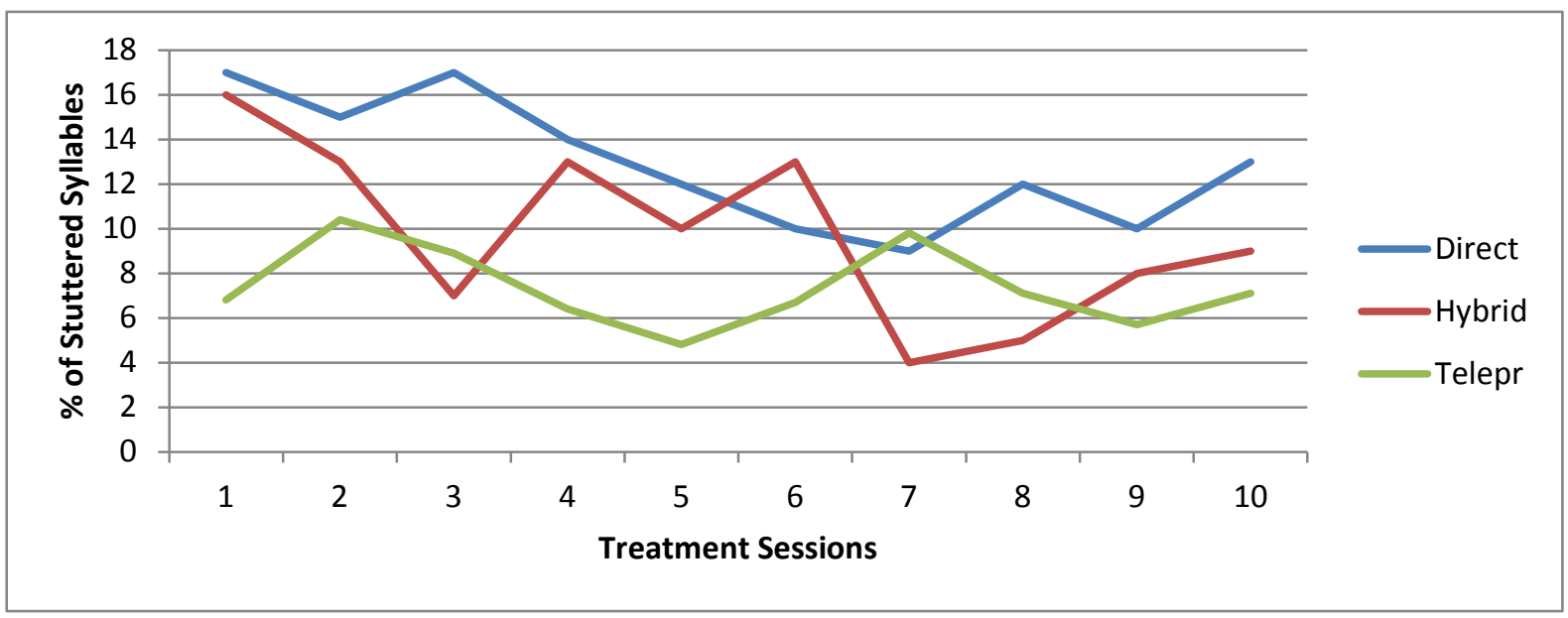

Figure 5. Participant 1: Percentage of stuttered syllables across intervention periods (Telep= Telepractice).

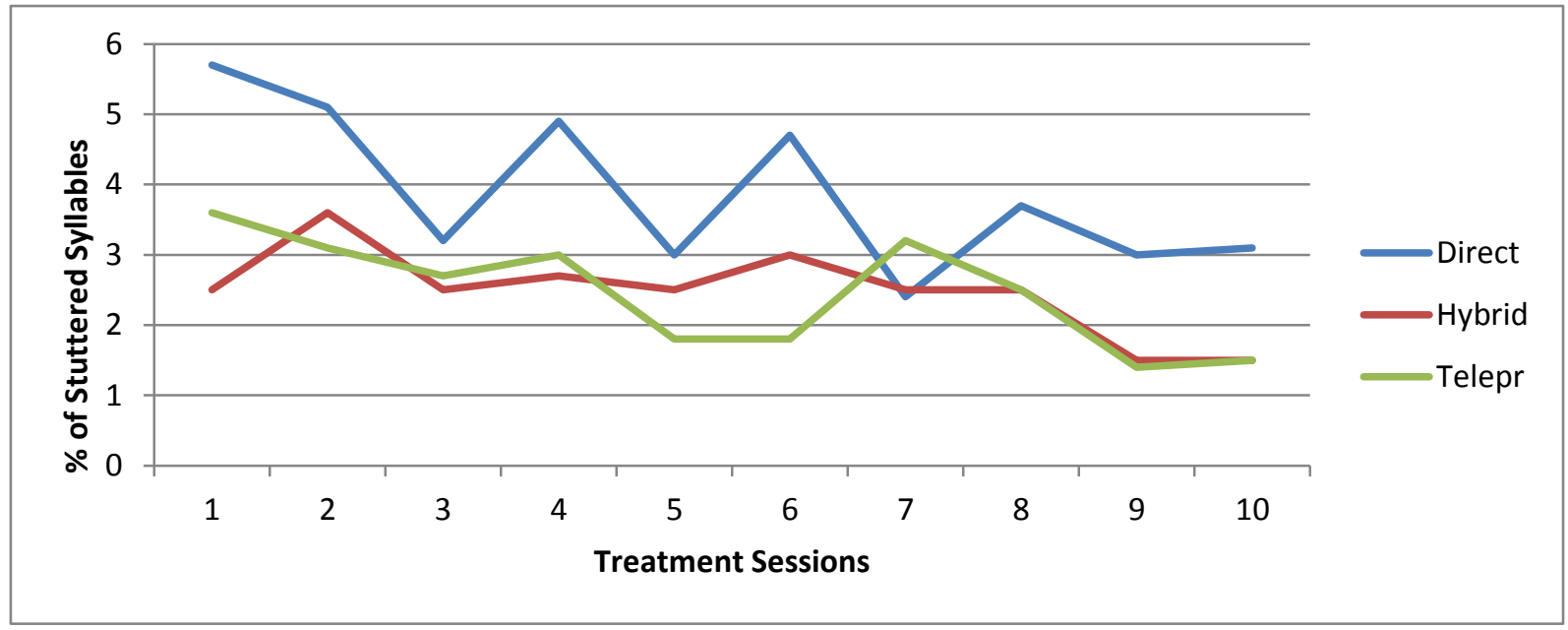

Figure 6. Participant 2: Percentage of stuttered syllables across intervention periods (Telep= Telepractice).

Figure 7 presents the $C A T-R$ scores prior to each treatment periods (Direct, Hybrid, and Telepractice). Participant 1 modestly improved her communication attitudes over the three treatment periods ( 15 to 13 ), however, the scores were well above the average of a child who does not stutter (8.71). Participant 2 demonstrated greater improvement (17 to 10), also outside the range for children who do not stutter. 


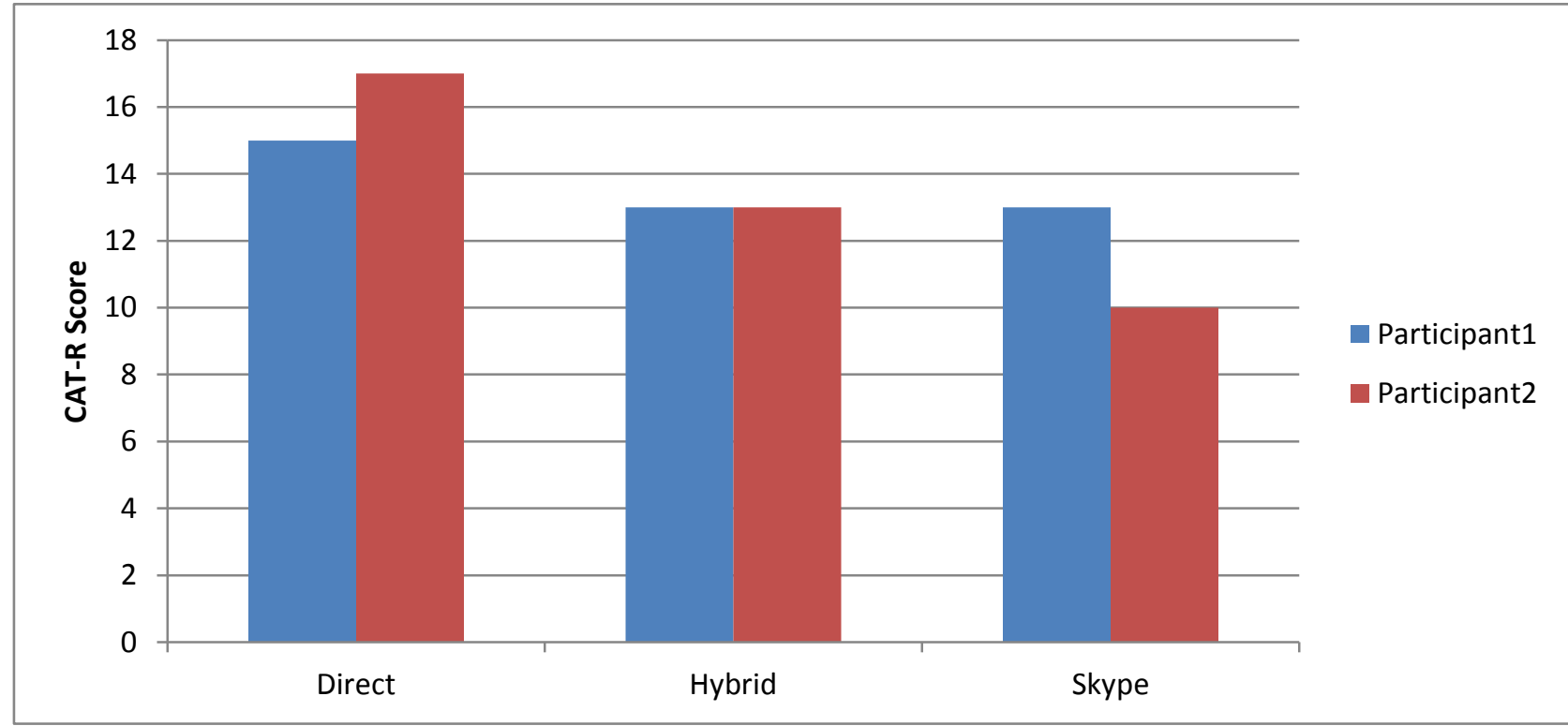

Figure 7. Communication Attitudes Test-Revised (CAT-R) scores for Participant 1 and Participant 2. [Mean for children who do not stutter: 8.17; Mean for children who stutter: 16.7].

To understand the experience of using telepractice for stuttering intervention, a 10 -item questionnaire was administered to the two children and their caregivers at the end of the telepractice periods. Table 1 presents the responses of the two caregivers.

Table 1. Caregivers' Perceptions of Telepractice Experience

\begin{tabular}{|l|l|l|l|l|l|}
\hline & SA & A & N & D & SD \\
\hline I believe my child enjoyed stuttering therapy over the Internet. & 2 & & & & \\
\hline Therapy sessions were scheduled at a convenient time. & 1 & 1 & & & \\
\hline Internet did not allow for consultation with the therapist. & & & & 1 & 1 \\
\hline I observed improvement in my child's fluency this semester. & & & 2 & & \\
\hline I prefer face-to-face therapy. & & 1 & & & 1 \\
\hline I missed observing treatment sessions. & & & 1 & 1 & \\
\hline Internet therapy gave me more time in my weekly schedule. & 2 & & & & \\
\hline I saved time and gas money with the Internet schedule. & 2 & & & & \\
\hline The increased number of sessions was valuable for my child. & & 1 & 1 & & \\
\hline Internet therapy did not allow me to discuss progress with the supervisor. & & 1 & & & 1 \\
\hline
\end{tabular}

Note. Numbers represent responses in the categories of SA (Strongly Agree), A (Agree), N (Neutral), D (Disagree), and SD (Strongly disagree).

The two respondents to this survey did agree that telepractice was very convenient and allowed them to have more flexibility in their weekly schedules, and they both agreed that their child had a positive experience. The two parents were split over the preference of direct treatment and telepractice. One parent commented "face-to-face therapy is a necessity; Skype is a great refresher/review." Both parents responded that they did not miss observing therapy sessions, and both perceived they could consult with the therapist concerning their child's progress.
Table 2 represents the responses of the two children about their experience of treatment via telepractice. There was agreement between the two participants about enjoying their treatment over the Internet and that telepractice afforded them more time in their weekly schedules. However, one child preferred coming to the campus facilities over telepractice. Both children felt comfortable with the technology and had no intimidations about completing therapy activities via the Internet. 
Table 2. Participants' Perceptions of Telepractice Experience

\begin{tabular}{|l|l|l|l|l|l|}
\hline & SA & A & N & D & SD \\
\hline I thought therapy on the Internet was fun. & 1 & 1 & & & \\
\hline I liked being home for therapy rather than traveling to a speech center. & 1 & & & 1 & \\
\hline It was hard to practice my fluent speech over the Internet. & & & & 1 & 1 \\
\hline Three days of therapy each week made me practice my fluent speech. & & 2 & & & \\
\hline I prefer coming to a speech center for therapy. & & 1 & 1 & & \\
\hline I enjoyed the activities that my therapist presented. & & 1 & 1 & & \\
\hline Internet therapy gave me more time in my weekly schedule. & 1 & 1 & & & \\
\hline Sometimes I didn't understand what I was supposed to do in therapy. & & & 1 & 1 & \\
\hline I did not like talking in front of the computer. & & & & 2 \\
\hline Overall, my speech has improved. & 1 & 1 & & & \\
\hline
\end{tabular}

Note. Numbers represent response in categories of SA (Strongly Agree, A (Agree), N (Neutral), D (Disagree), SD (Strongly disagree)

\section{DISCUSSION}

This study evaluated the use of a telepractice model to improve and maintain fluency following treatment sessions using a direct service delivery model and a hybrid model. Participants included two 11-year old children who stutter.

Concerning the first research question (Did fluency increase, decrease or was it maintained across the service delivery models?) the results showed that fluency improved most dramatically following the direct treatment period and continued to make modest improvements across the other service delivery models. These gains were represented both in the SSI-4 severity rating index and in the percentage of stuttered syllables in a short speaking task. As to why there was such a large decrease in stuttering following the direct intervention period, one could argue that greater gains in fluency often take place after the client has initially learned management or fluency shaping techniques, and more subtle improvements are learned over time in various speaking situations. One of the primary measurements was the percentage of stuttered syllables in a short speaking task; it could be argued that this measurement is somewhat contrived and not a natural speaking situation. However, it was a fairly neutral and consistent task in order to collect data across the three treatment periods. Obtaining data from more natural speaking situations (e.g., arguing with a younger sibling; explaining to a parent the need for a raise in allowance; ordering from the drive-up window, etc.) is valuable and these kinds of activities were done over the course of treatment. However, because some situations are more emotionally charged than others, and therefore affect the variability of the stuttering, it would be inappropriate to compare these different kinds of speaking situations across the treatment periods.
Each of the children in this study attended intervention sessions weekly, however, due to the busy schedules of a modern family, treatment fidelity was not $100 \%$. For Participant 1, the percentage of sessions attended was $89 \%$ for direct, $84 \%$ for the hybrid, and $74 \%$ for the telepractice period. For Participant 2, percentage of sessions attended was $88 \%$ for direct, $88 \%$ for hybrid, and $60 \%$ for the telepractice period. Interestingly, even though the participants and their caregivers responded positively to the telepractice service delivery model, primarily because of the convenience of home intervention, the attendance during those sessions was lower for both participants than for the other service delivery models. It could be speculated that weekly appointments outside of the home require more preparation and become more of a priority in a family's weekly schedule.

Communication attitudes were recorded by the questionnaire CAT-R. Each participant demonstrated lower scores (improved communication attitudes) following the first treatment period, however, scores remained consistent for Participant 1 after the next two treatment periods. Although it is assumed that positive attitudes toward speech will improve as fluency increases, most researchers believe negative speaking attitudes need to be directly addressed (Reardon-Reeves \& Yaruss, 2013). Neither of the two children in this study had communication scores within the range of children who do not stutter, and this might represent a need for more activities that addressed any negative communication attitudes. Also, it could be argued that more recent assessments of negative communication attitudes (e.g., Overall Assessment of the Speaker's Experience of Stuttering; Yaruss \& Quesal, 2010) might have yielded a more sensitive analysis. During the first two intervention periods, speaking situations that increased anxieties were discussed and practiced by the clinicians and the participants. Some of these included group presentations, ordering food at the campus restaurant, or asking someone on campus for directions. These kinds of transfer activities and exploring the participants' reactions 
were not possible to do online, in this study. At the same time, however, negative communication attitudes (and positive communication attitudes) were discussed each week when participants read from their weekly speech journals that describe a good speaking day or a day that was harder than others. A limitation of telepractice is that it does not easily allow for transfer or group activities where a speaker's anxieties or negative communication attitudes might be addressed.

Parents of the children who participated in this treatment study reported that service via the Internet helped them be more flexible in their weekly schedules. This benefit of having treatment in the home as opposed to travelling to an outpatient clinic has been documented in the literature (Karp et al., 2000). Despite not having in-person contact with the therapist, the caregivers did not feel that services over the Internet interfered with their ability to consult with the therapist delivering the service. This response was well received because the therapists often included a parent or a sibling during one of the therapy activities. However, the parent of Participant 2 commented that even though telepractice was very convenient, he felt that the hybrid model was preferable and that direct contact with the therapist was critical for both caregiver and client.

Responses from the children who participated in the study indicated that they had a positive experience with therapy over the Internet. Both children were very comfortable with the technology and felt very natural in practicing their fluency over the Internet. They were split over whether they preferred coming to the campus facilities as opposed to receiving therapy in the home. Participant 1 responded that she would prefer to come to the speech center; her mother observed that travel to the clinic provided some opportunity to defer homework activities.

Overall, both caregivers and children had positive experiences with intervention via telepractice. Improvements in fluency were demonstrated across all treatment delivery models, including telepractice. In the two children studied, the use of telepractice enabled successful individual therapy sessions, as well as progress toward long-term goals. If there was a regression in fluency, one might infer that telepractice may not be a suitable delivery model for therapy for a particular client, however, such was not the case in this study.

The graduate students who provided the intervention via telepractice found the experience to be a novel one and welcomed the opportunity to gain exposure to an emerging service delivery model in the field. In concert with previous research that detailed the disadvantages of telepractice, the students observed that some data collection might not be reliable due to sporadic interruptions in Internet connectivity. In general, they felt that the sessions were less personable than in-person contact and they could not develop personalized transfer activities. On the other hand, the therapists found that it was easy to involve parents and siblings in a natural environment using telepractice. Finally, they felt they had to be more creative to plan activities via telepractice.

\section{LIMITATIONS}

Because this study was limited to two participants, the results cannot be generalized. In fact, each of the children had various degrees of positive outcomes; this might or might not be due to the treatment service delivery models, but to the children's ability to cope with their stuttering at that point in their lives. The present study did not attempt to compare the effectiveness of a direct model with a telepractice model since both children began their intervention in a direct model. Given the importance that many clinical researchers in stuttering place on establishing rapport and clinician/client trust (Conture, 2001; Guitar, 2013; Manning, 1996), beginning with a telepractice model might represent a challenge. However, this is not outside the confines of further research and a future study would be appropriate to investigate whether similar significant gains could be achieved in the first treatment period of stuttering intervention via telepractice.

Another limitation of this study was the lack of reliability of the weekly data collection. Only the data from the SSI-4 was recorded and reviewed by two raters (i.e., clinician and author) for accuracy. Reliability of stuttered syllables in a speaking task was monitored during a training period before treatment began and over the first several sessions. The graduate students all achieved $90 \%$ accuracy of stuttered syllables in a speaking task the first week of their treatment with the participants.

Although treatment goals and methods, as well as data collection protocols were consistent across all clinicians, the fact that each participant had a different therapist in each of the three delivery models could have affected treatment outcomes. At the same time, because the children had rotating therapists, it decreased the familiarity effect which could have resulted in false improvements in stuttering percentages. Arguments can be made that fluency measures were not conducted in natural communication situations (e.g., speaking with peers at school, or with family at a restaurant, etc.) and therefore the results might not provide a true representation of the child's fluency skills. Future studies will need to provide options to obtain fluency samples in a variety of speaking situations. Despite these limitations, this study demonstrated that the use of telepractice offers a cost-effective service delivery model for stuttering intervention. This tentatively suggests that intervention via telepractice can be a viable means to help maintain gains in fluency. 


\section{ACKNOWLEDGEMENT}

The author would like to thank the many graduate students who provided intervention to the two participants over the course of this study. These include: Marie Morrison, Allyssa Conti, Maranda Cochran, Elizabeth Wheeler, Katherine Green, and Erin Viruleg.

\section{REFERENCES}

American Speech-Language-Hearing Association. (2014). Professional issues: Telepractice. Available from http://www.asha.org/Practice-Portal/ProfessionalIssues/Telepractice/

Armfield, N.R., Gray, L.C., \& Smith, A.C. (2012). Clinical use of Skype: A review of the evidence. Journal of Telemedicine and Telecare, 18, 125-127.

Blaiser, K.M., Behl, D., \& Callow-Heusser, C. (2013). Measuring costs and outcomes of tele-intervention when serving families of children who are deaf/hard-ofhearing. International Journal of Telerehabilitation, 5(2), 3-10..

Brutten, G.J. (1997). Communication Attitudes Test. University of Nebraska-Lincoln. Retrieved from http://cens.unl.edu/fluency/pdfs/test.pdf

Carey, B., O'Brian, S., Onslow, M., Block, S., Jones, M., \& Packman, A. (2010). Randomized controlled noninferiority trial of a telehealth treatment for chronic stuttering: The Camperdown Program. International Journal of Language and Communication Disorders, 45, 108-120.

Cohn, E.R. (2012). Tele-ethics in telepractice for communication disorders. Perspectives on Telepractice, 2(1), 3-15.

Cohn, E.R., Brannon, J., \& Cason, J. (2011). Resolving barriers to licensure portability for telerehabilitation professionals. International Journal of Telerehabilitation, 3(2), 31-33.

Conture, E.G. (2001). Stuttering: Its nature, diagnosis, and treatment. Boston: Allyn and Bacon.

Denton, D.R. (2003). Ethical and legal issues related to telepractice. Seminars in Speech and Language, 24, 313-322.

Grogan-Johnson, S., Alvares, R., Rowan, L., \& Creaghead, N. (2010). A pilot study comparing the effectiveness of speech language therapy provided by telemedicine with conventional on-site therapy. Journal of Telemedicine and Telecare, 16, 134-139.

Halpern, A.E., Ramig, L.O., Matos, C.E, Petska-Cable, J.A., Spielman, J.L., Pogoda, J.M., ...McFarland, D.H. (2012). Innovative technology for the assisted delivery of intensive voice treatment (LSVT LOUD) for
Parkinson disease. American Journal of Speech Language Pathology, 21, 354-367.

Harris, E., Onslow, M., Packman, A., Harrison, E., \& Menzies, R. (2002). An experimental investigation of the impact of the Lidcombe Program on early stuttering. Journal of Fluency Disorders, 27, 203-214.

Harrison, E., Wilson, L., \& Onslow, M. (1999). Distance intervention for early stuttering with the Lidcombe Program on early stuttering. Advances in Speech Language Pathology, 1, 31-36.

Hill, A.J., Theodoros, D.G., Russell, T.G., Cahill, L.M., \& Ward, E.C. (2006). An Internet-based telerehabilitation system for the assessment of motor speech disorders: A pilot study. American Journal of Speech-Language Pathology, 15, 45-56.

Howell, S., Tripoliti, E., \& Pring, T.R. (2009). Delivering the Lee Silverman Voice Treatment (LSVT) by web camera: A feasibility study. International Journal of Language and Communication Disorders, 44, 287-300.

Irani, F., \& Gabel, R. (2011). Intensive stuttering therapy with telepractice follow-up: A case study. Perspectives on Fluency and Fluency Disorders, 21, 11-21.

Gabel, R., Irani, F., Palasik, S., Swartz, E., \& Hughes, C. (2010). Treatment outcomes of the intensive stuttering therapy for adolescents and adults. In A.E. Harris (Ed.), Speech Disorders: Causes, Treatment, and Social Effects (pp. 139-159). New York, NY: Nova Science Publishers.

Georgeadis, A.C. Brennan, D.M., Barker, L.M., and Baron, C.R. (2004). Story retelling performance and subject feedback from adults with neurogenic impairments in both face-to-face and remote videoconference settings. Clinical Aphasiology, 18, 639-652.

Guitar, B. (2013). Stuttering: An integrated approach (4th edition). Baltimore: Lippincott Williams \& Wilkins.

Karp, W., Grigsby, R., McSwiggan-Hardin, M., PurselyCrotteau, S., Adams, L., Bell, W.,...Kanto, W.P. (2000). Use of telemedicine for children with special health care needs. Pediatrics, 105, 843-847.

Kully, D. (2000). Telehealth in speech pathology: Applications to the treatment of stuttering. Journal of Telemedicine and Telecare, 6, 39-41.

Lincoln, M.A., \& Onslow, M. (1997). Long-term outcome of early intervention for stuttering. American Journal of Speech-Language Pathology, 6, 51-58.

Lewis, C., Packman, A., Onslow, M., Simpson, J.M., \& Jones, M. (2008). A phase II trial of telehealth delivery of the Lidcombe Program of early stuttering intervention. American Journal of Speech-Language Pathology, 17, 139-149.

Manning, W.H. (1996). Clinical decision making in the diagnosis and treatment of fluency disorders. Boston: Delmar Publishers. 
Mashima, P.A., Birkmire-Peters, D.P., Holtel, M.R., \& Syms, M.J. (1999). Telehealth applications in speechlanguage pathology. Journal of Healthcare Information Management, 13, 71-78.

O’Brian, S., Onslow, M., Cream, A., \& Packman, A. (2003). The Camperdown Program: Outcome of a new prolonged-speech treatment model. Journal of Speech, Language, Hearing Research, 46, 933-946.

O'Brian, S., Packman, A., \& Onslow, M. (2008). Telehealth delivery of the Camperdown Program for adults who stutter. Journal of Speech, Language, and Hearing Research, 51, 184-195.

O'Brain, S., Smith, K., \& Onslow, M. (2014). Webcam delivery of the Lidcombe Program for early stuttering: A phase I clinical trial. Journal of Speech, Language, and Hearing Research, 57, 825-830.

Onslow, M., Packman, A., \& Harrison, E. (2003). The Lidcombe Program of Early Stuttering Intervention: $A$ clinician's guide. Austin, TX: Pro-Ed

Reardon-Reeves, N. \& Yaruss, J.S. (2013). School-age stuttering therapy: A practical guide. McKinney, TX: Stuttering Therapy Resources, Inc.

Riley, G. (2009). Stuttering Severity Instrument ( $4^{\text {th }}$ ed.). Austin, TX: Pro-Ed.
Sicotte, C., Lehoux, P., Fortier-Blanc, J., \& Leblanc, Y. (2003). Feasibility and outcome evaluation of a telemedicine application in speech-language pathology. Journal of Telemedicine and Telecare, 9, 253-258.

Schwartz, H. (1999). A primer for stuttering therapy. Boston: Allyn and Bacon.

Theodoros, D., Hill, A., Russell, T., Ward, E., \& Wooten, R. (2008). Assessing acquired language disorders in adults via the Internet. Telemedicine and e-Health, 14, 552-559.

Wertz, R.T., Dronkers, N.F., Bernstein-Ellis, E., Shubitowski, Y., Elman, R., Shenaut, G.K.,... Deal, J.L. (1992). Potential of telephonic and television technology for appraising and diagnosing neurogenic communication disorders in remote settings. Aphasiology, 6, 195-202.

Wilson, L., Onslow, M., \& Lincoln, M. (2004). Telehealth adaptation of The Lidcombe Program of early stuttering intervention: Five case studies. American Journal of Speech-Language Pathology, 13, 81-93.

Yaruss, J.S. (1998). Real-time analysis of speech fluency: Procedures and reliability training. American Journal of Speech-Language Pathology, 7, 25-37.

Yaruss, J.S. \& Quesal, R. (2010). Overall assessment of the speaker's experience of stuttering. Minneapolis, MN: Pearson. 
